\title{
How to Analyze Air Quality During the COVID-19 Pandemic? An Answer using Grey Systems
}

\author{
Alexi Delgado ${ }^{1}$, Denilson Pongo ${ }^{2}$, Katherine Felipa $^{3}$, Kiara Saavedra ${ }^{4}$, Lorena Torres ${ }^{5}$, Lourdes Serpa $^{6}$, Ch. $_{\text {Carbajal }}{ }^{7}$ \\ Mining Engineering Section, Pontificia Universidad Católica del Perú, Lima, Peru ${ }^{1}$ \\ Environmental Engineering Department, National University of Engineering, Lima, Peru ${ }^{2,3,4,5,6}$ \\ Administration Program, Universidad de Ciencias y Humanidades, Lima, Peru ${ }^{7}$
}

\begin{abstract}
The Peruvian government declared a State of National Emergency due to the spread of COVID-19 where the closure of businesses, companies and home isolation was imposed from $03 / 15 / 2020$ to $06 / 30 / 2020$. In this context, the research focused on analyzing the characteristics of the air quality in Lima during said period compared to its similar in 2018 and 2019, for this purpose, data from two air quality monitoring stations in PM2.5, PM10, CO and NO2 concentrations and the quality levels given by the Air Quality Index (INCA) were used for further processing with the Grey Clustering method, which is based on grey systems. The results showed that during the quarantine, air quality improved significantly, specifically the northern area of Lima, which was favored by the meteorological conditions that will be classified as good quality as well as the reduction of PM10 by $46 \%$ and PM2.5 in $45 \%$ to a lesser extent, NO2 by $17 \%$ and CO in $11 \%$, unlike the southern zone which, although it showed an improvement, it is still classified as moderate quality with reductions in PM10 by 26\%, PM2.5 by $27 \%$, CO by 19\%,; however the concentration NO2 registered a non-significant increase of $2 \%$. This behaviour is explained by the lower height of the thermal inversion layer, therefore less space for the dispersion of pollutants. Finally, the study obtains essential information for regulatory agencies as it allows understanding the relationship between air quality and control measures at emission sources for the development of public policies on public health and the environment.
\end{abstract}

Keywords-Air quality; COVID 19; grey systems; grey clustering

\section{INTRODUCTION}

On March 11, 2020, the World Health Organization (WHO) declared that the COVID 19 - disease caused by the new coronavirus SARS-CoV-2-went from being an epidemic to a pandemic [1]. In Perú, the first confirmed case was reported on March 6, 2020, in Lima, a young man had arrived from a trip to the European continent. To date March 16, there were 86 positive cases of coronavirus, being Lima the department with the highest number (70 cases) [2].

To control the increase in the number of cases confirmed by coronavirus, Peru declared a national state of emergency for a period of 15 days, during which it was decided to establish mandatory social isolation (quarantine), a measure that came into effect March 16. During the quarantine period, public access to premises and establishments (restaurants, museums, cultural, sports and leisure activities, among others) was suspended, except for commercial establishments for the acquisition of food and basic necessities. Due to the increase in coronavirus cases, the quarantine was extended until June 30.

During and after the declaration of the state of emergency in the country, an extraordinary measure to stop the advance of the coronavirus (COVID-19), it was possible to verify the downward trend in air pollutants such as particulate matter smaller than $2.5 \mu \mathrm{m}$ diameter (PM 2.5), Lima. During the quarantine days, the environment had a respite and the improvement was evident, as demonstrated by the measurements taken by MINAM which indicated that the air quality in Lima reached the levels recommended by World Health Organization. In addition, there was a reduction in the average concentrations of other parameters, which meant a gradual improvement in air quality in the city, increased by the effect of the reduction in emissions due to the suppression of the flow of vehicles as a result of the mandatory social isolation.

Likewise, in the international context concerning air quality, there is evidence in research conducted in several countries, for example [3], analyzed the results of air quality monitoring and meteorological data recorded in Wuhan in the period from January to May 2020, finding that the Air Quality Index (AQI) reached 90.1\% in January-April 2020 being significantly higher than the index recorded in 2017 of $71.9 \%$, in 2018 of $70 \%$ and in 2019 of $72.5 \%$, they also found that $\mathrm{SO} 2, \mathrm{NO} 2, \mathrm{CO}, \mathrm{PM} 10$ and PM2.5 concentrations decreased by $6.95 \%, 38.23 \%, 18.24 \%, 30.25 \%$ and $32.92 \%$ respectively from 2019 to 2020. Moreover [4], in Brazil, also evaluated the impact of the partial closure of activities such as shopping centers, restaurants, schools and universities on air quality in the state of São Paulo as a measure to stop the advance of COVID-19, for this they analyzed the monthly average concentrations of February, March and April from three air quality stations: Marginal Tietê, Marginal Pinheiros and Downtonwn from the period 2015-2019 for the registered in 2020, they observed significant reductions of NO up to $77.3 \%$, NO2 by up to $54.3 \%, \mathrm{CO}$ by up to $64.8 \%$ and PM 2.5 by $29.8 \%$.

For the development of the assessment, the Grey Clustering method, which is based on grey systems, specially, the Centerpoint Triangular Whitenization Weight Functions (CTWF) method and the Entropy weighting method, based on Shannon's entropy, to calculate objective weights for the evaluation criteria within the CTWF method, was used. In this sense, the objective of this study was to evaluate air quality using an artificial intelligence model based on the Grey 
Clustering method and Shannon entropy in Lima, Peru before and during the period of total confinement due to the COVID19 pandemic [5].

\section{MATERIALS AND METHODS}

The impact of total confinement on air quality in the city of Metropolitan Lima was evaluated by analyzing the records of the monitoring stations of the National Meteorology and Hydrology Service (SENAMHI by its Spanish acronym) regarding the concentrations of PM10, PM2.5, NO2 and CO. from March 16 to June 30, 2021 (period of total confinement) and its similar in 2018 and 2019.

\section{A. Metropolitan Lima}

Lima is the capital of Peru and the fifth most populous city in Latin America with a population of 9,485,405 people [5]. It is located on the shores of the Pacific Ocean on the Central Coast of Peru with an area of 2,819 km2 as shown in Fig. 1.

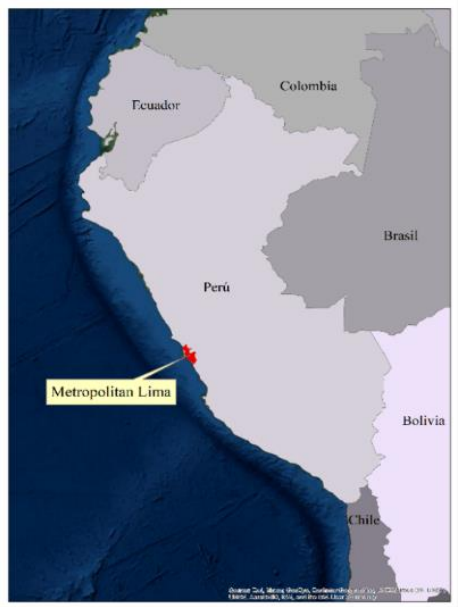

Fig. 1. Geographical Location of Metropolitan Lima, Peru.

According to a study carried out by MINAM in 2014 on mortality and morbidity as a result of air pollution in Metropolitan Lima, 1220 cases of deaths associated with PM10 pollution were found, with respiratory diseases (468 cases) and cardiovascular diseases (165 cases) of higher incidence, being the vehicle fleet the main source of contamination characteristic of an old low-maintenance vehicle fleet [6] [7].

\section{B. Methodology}

In this section, we describe the Grey Clustering method (GCM), which can be described as follows: first, suppose the area is set of $\mathrm{m}$ objects, a set of $\mathrm{n}$ criteria, and a set of s Grey classes, according to the sample value $(i=1,2, \ldots, m ; j=$ $1,2, \ldots, n)$. Then, the steps of the method can be developed with the following points according to different research.

\section{Step 1: Determination of Center Points}

The ranges of the criteria are divided into 4 Grey classes, and then their central points are $\lambda 1, \lambda 2, \ldots, \lambda s$, this is determined by the Air Quality Index (INCA).

\section{Step 2: Dimension Removal}

Dimension Removal of values of the Environmental Quality Index: For this second step we have the matrix "I" of values of the Environmental Quality Index $I=\{I i j, i=$ $1,2,3, \ldots, m ; j=1,2,3, \ldots n\}$, in which " $i$ " represents the central points of the air quality parameters: PM10 (ug / m3), PM 2.5 (ug / m3), NO2 (ug / m3)) and CO (ug / m3) and " $j$ " are the quality levels according to INCA: Good, Moderate, Bad and Threshold of care. And we proceed to normalize said matrix into a new matrix "Aij", using (1).

$A_{i j}=\left(\frac{I_{i j}}{\frac{\sum_{j=1}^{n} I_{i j}}{n}}\right)$

Dimension Removal of Sampling data: In the same way as the dimension removal of standard data, it is performed for sampling data, whose matrix is $\quad M=\{M i j, i=1,2,3, \ldots, m ; j=1,2,3, \ldots, n\}$, in which " $i$ " represents the sampled air quality parameters and " $j$ " are the sampling stations. Followed, we proceed to normalize the matrix M in a new matrix "Bij", using (2).

$B_{i j}=\left(\frac{M_{i j}}{\frac{\sum_{j=1}^{n} M_{i j}}{n}}\right)$

Step 3: Triangular Functions and their Values

The Grey classes are expanded according to the analyzed air quality parameters, this provides us with four quality levels for each parameter, so we will have 4 functions for each parameter or criterion used. These functions will have the form as shown in (3).

$f_{j}^{k}\left(X_{i j}\right)$

Then, we have the triangular functions as represented in (4) (6).

$f_{j}^{2}\left(X_{i j}\right)=\left\{0, x \notin\left[0, \lambda_{j}^{2}\right] ; 1, x \in\left[0, \lambda_{j}^{2}\right] ; \frac{\lambda_{j}^{2}-x}{\lambda_{j}^{1}-\lambda_{j}^{2}}, x \in\left[\lambda_{j}^{1}, \lambda_{j}^{2}\right]\right\}$

$f_{j}^{k}\left(X_{i j}\right)=$

$\left\{0, x \notin\left[\lambda_{j}^{k-1}, \lambda_{j}^{k+1}\right] ; \frac{\lambda_{j}^{k+2}-x}{\lambda_{j}^{k-1}-\lambda_{j}^{k}}, x \in\left[\lambda_{j}^{k}, \lambda_{j}^{k+1}\right] ; \frac{x-\lambda_{j}^{k-1}}{\lambda_{j}^{k}-\lambda_{j}^{k+2}}, x \in\right.$

$\left.\left[\lambda_{j}^{k-1}, \lambda_{j}^{k}\right]\right\}$

$f_{j}^{4}\left(X_{i j}\right)=\left\{0, x \notin\left[\lambda_{j}^{3},+\infty\right] ; \frac{x-\lambda_{j}^{3}}{\lambda_{j}^{4}-\lambda_{j}^{3}}, x \in\left[\lambda_{j}^{3}, \lambda_{j}^{4}\right] ; 1, x \in\right.$

$\left.\left[\lambda_{j}^{4},+\infty\right]\right\}$

Step 4: Determination of the Weight for each Criteria

To eliminate the uncertainty regarding the calculation of the weight of the criteria, the Shannon entropy weighting method will be applied. Shannon developed measure H which satisfies the following properties for all pi within an estimated joint probability distribution [7] [8].

- $H$ is a continuous positive function.

- $\quad H$ should be a monotonic increasing function of $n$ if all $p i$ is equivalent and $p i=1 / n$.

- For all $n \geq 2, H\left(p_{1}, p_{2}, \ldots, p_{n}\right)=h\left(p_{1}, p_{2}, \ldots, p_{n}\right)+$ $\left(p_{1}+p_{2}\right) H\left(\frac{p_{1}}{p_{1}+p_{2}}, \frac{p_{2}}{p_{1}+p_{2}}\right)$. 
Shannon showed that the only function which satisfies these properties is obtained by (7).

$H_{\text {Shannon }}=-\sum_{i}^{n} p_{i} \log \left(p_{i}\right)$

Where: $0 \leq p_{i} \leq 1 ; \sum_{j=1}^{n} p_{i}=1$.

As shown above, it is assumed that there are m objects and $n$ evaluation criteria, which form the following matrix $X=$ $\left\{x_{i j}, i=1,2, \ldots, m ; j=1,2, \ldots, n\right\}$ [9]. After that, the steps to determine the weights under Shannon entropy are shown:

1) The matrix $X=\left\{x_{i j}, i=1,2, \ldots, m ; j=1,2, \ldots, n\right\}$ is normalized for each criterion $C_{j}(j=1,2, \ldots, n)$. The normalization evaluates $P i j$ are calculated using (8).

$f_{j}^{1}\left(x_{i j}\right) P_{i j}=\frac{x_{i j}}{\sum_{i=1}^{m} x_{i j}}$

2) The entropy of each criterion is calculated using (9).

$H_{j}=-k \sum_{i=1}^{m} P_{i j} \ln \left(p_{i}\right)$

Where $k$ is a constant, $k=(\ln (m))^{-1}$

3) The degree of divergence of the intrinsic information in each criterion $C j$ is calculated using (10).

$\operatorname{div}_{j}=1-H_{j}$

4) In the weight entropy $w j$ of each criterion $C j$, we have to use (11).

$w_{j}=n_{j}=\frac{d i v_{j}}{\sum_{j=1}^{n} d i v_{j}}$

Step 5: Determination of the Clustering coefficient

The classification coefficient " $i k$ " for each sampling station $" i=1,2,3, \ldots, m "$, with respect to the grey classes $" j=$ $1,2,3, \ldots n "$, is calculated using (12).

$\sigma_{i}^{k}=\sum_{j=1}^{n} f_{j}^{k}\left(X_{i j}\right) n j$

Where the triangular function of each class of Grey with respect to each criterion is analyzed, while $n j$ are the weights of each criterion [9].

Step 6: Results using the highest Clustering coefficient

Finally, as the last step, the maximum value of the clustering coefficient is calculated [10]:

$\max _{1 \leq k \leq s}\left\{\sigma_{i}^{k}\right\}=\sigma_{i}^{k}$

In this way, it will be observed what kind of flock is found in each station studied.

\section{RESUltS AND DISCUSSION}

\section{A. Method Application}

Step 1: Definition of Study Objects

Data from two air quality monitoring stations in Villa María del Triunfo and Carabayllo located south and north of Lima, respectively, were used; both stations managed by the National Meteorology and Hydrology Service (also known as
SENAMHI by its Spanish acronym) of Peru. The parameters analyzed were nitrogen dioxide (NO2), carbon monoxide (CO), particulate matter smaller than $10 \mu \mathrm{m}$ in diameter (PM10) and smaller than $2.5 \mu \mathrm{m}$ in diameter (PM2.5) during the period of mandatory social isolation, declared by the Peruvian State in the framework of the National Emergency because of the COVID-19 pandemic from March 16 to June 30, 2020 and what registered in the same period in 2018 and 2019. Table I details the location of the stations represented in Fig. 2.

TABLE I. AIR QUALity Monitoring Stations in METROPOLITAN LIMA

\begin{tabular}{|l|l|l|l|l|}
\hline \multirow{2}{*}{ Station } & \multirow{2}{*}{ Code } & \multicolumn{2}{|l|}{ Coordinates (WGS84) } & \multirow{2}{*}{$\begin{array}{l}\text { Sampling } \\
\text { height }\end{array}$} \\
\cline { 3 - 4 } & & East & North & $3 \mathrm{~m}$ \\
\hline $\begin{array}{l}\text { Villa Maria } \\
\text { del Triunfo }\end{array}$ & VMT & 291084 & 8654309 & $6 \mathrm{~m}$ \\
\hline Carabayllo & CAR & 278498 & 8683451 & 6 \\
\hline
\end{tabular}

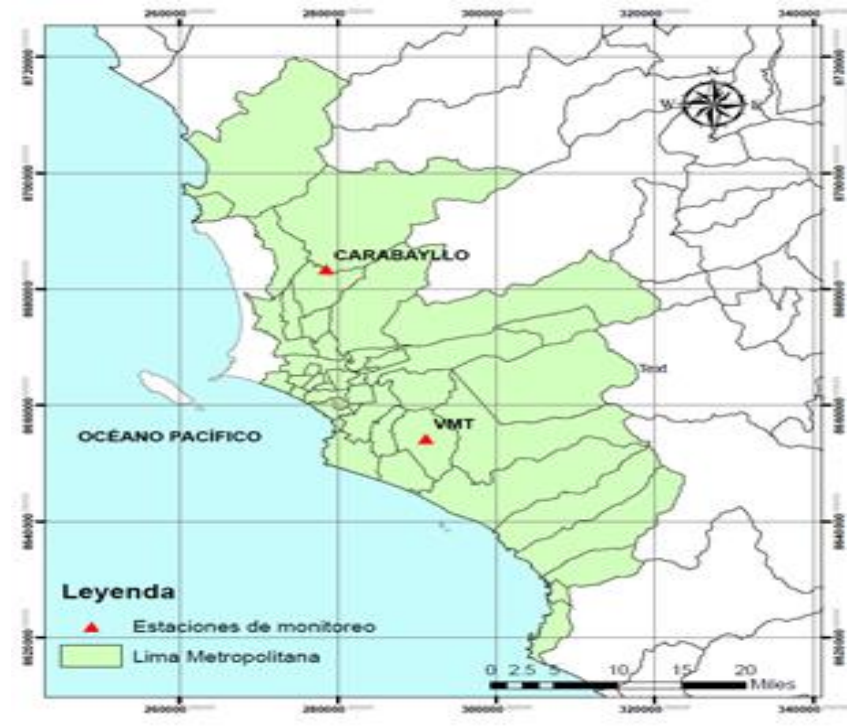

Fig. 2. Air Quality Monitoring Stations in Metropolitan Lima, Peru.

\section{Step 2: Definition of Criteria}

The evaluation criteria for the present study are determined by the air quality parameters presented in Table II.

TABLE II. CRITERIA FOR AIR QUALITY ASSESSMENT

\begin{tabular}{|l|l|c|}
\hline Criteria & Units & Notation \\
\hline $\mathrm{PM}_{10}$ & $\mathrm{ug} / \mathrm{m}^{3}$ & $C_{1}$ \\
\hline $\mathrm{PM}_{2.5}$ & $\mathrm{ug} / \mathrm{m}^{3}$ & $C_{2}$ \\
\hline $\mathrm{NO}_{2}$ & $\mathrm{ug} / \mathrm{m}^{3}$ & $C_{3}$ \\
\hline $\mathrm{CO}$ & $\mathrm{ug} / \mathrm{m}^{3}$ & $C_{4}$ \\
\hline
\end{tabular}

Step 3: Definition of the Grey classes

The classes for the evaluation are four and are based on the air quality levels according to the Air Quality index in Peru according to RM-N $\mathrm{N}^{\circ}$-181-2016-MINAM and D.S. $\mathrm{N}^{\circ}$ 0032017-MINAM, which are presented in Table III. 
TABLE III. AIR QUALITY INDEX STANDARD DATA FOR AIR QUALITY ASSESSMENT

\begin{tabular}{|l|l|l|l|l|}
\hline \multirow{2}{*}{ Criteria } & \multicolumn{4}{|l|}{ Grey Classes } \\
\cline { 2 - 5 } & Good & Moderate & Poor & Threshold of Care \\
\hline $\mathrm{PM}_{10}$ & $0-50$ & $51-100$ & $101-200$ & $>200$ \\
\hline $\mathrm{PM}_{2.5}$ & $0-12.5$ & $12.6-25$ & $25.1-125$ & $>125$ \\
\hline $\mathrm{NO}_{2}$ & $0-100$ & $101-200$ & $201-300$ & $>300$ \\
\hline $\mathrm{CO}$ & $0-5049$ & $5050-10049$ & $10050-15049$ & $>15050$ \\
\hline
\end{tabular}

Step 4: Calculations using the CTWF Method

The calculations based on the Grey Clustering method are presented below:

1) Based on the air quality index in Peru, the central values of the parameters to be analysed are obtained. These values are shown in Table IV.

TABLE IV. Central Values of THE AIR Quality IndeX IN Peru

\begin{tabular}{|l|l|l|l|l|}
\hline Parameter & $\begin{array}{l}\text { Good } \\
\left(\boldsymbol{\lambda}_{\mathbf{1}}\right)\end{array}$ & $\begin{array}{l}\text { Moderate } \\
\left(\boldsymbol{\lambda}_{\mathbf{2}}\right)\end{array}$ & $\begin{array}{l}\text { Poor } \\
\left(\boldsymbol{\lambda}_{\mathbf{3}}\right)\end{array}$ & $\begin{array}{l}\text { Threshold } \\
\text { of care }\left(\boldsymbol{\lambda}_{\mathbf{4}}\right)\end{array}$ \\
\hline $\mathrm{PM}_{10}$ & 37.5 & 113.0 & 200.5 & 288.0 \\
\hline $\mathrm{PM}_{2.5}$ & 6.3 & 18.8 & 75.0 & 131.3 \\
\hline $\mathrm{NO}_{2}$ & 50.0 & 150.5 & 250.5 & 350.5 \\
\hline $\mathrm{CO}$ & 2524.5 & 7549.5 & 12549.5 & 17549.5 \\
\hline
\end{tabular}

2) The non-dimensioned standard values for each parameter, according to the air quality index in Peru, were determined through (1). These values are presented in Table V.

TABLE V. NON-Dimensional STANDARD VALUE OF THE AiR QUALity INDEX

\begin{tabular}{|c|l|l|l|l|}
\hline Parameter & $\begin{array}{l}\text { Good } \\
\left(\boldsymbol{\lambda}_{\mathbf{1}}\right)\end{array}$ & $\begin{array}{l}\text { Moderate } \\
\left(\boldsymbol{\lambda}_{\mathbf{2}}\right)\end{array}$ & $\begin{array}{l}\text { Poor } \\
\left(\boldsymbol{\lambda}_{\mathbf{3}}\right)\end{array}$ & $\begin{array}{l}\text { Threshold } \\
\text { of care }\left(\boldsymbol{\lambda}_{\mathbf{4}}\right)\end{array}$ \\
\hline$C_{1}$ & 0.235 & 0.707 & 1.255 & 1.803 \\
\hline$C_{2}$ & 0.108 & 0.325 & 1.297 & 2.270 \\
\hline$C_{3}$ & 0.250 & 0.751 & 1.250 & 1.749 \\
\hline$C_{4}$ & 0.251 & 0.752 & 1.250 & 1.747 \\
\hline
\end{tabular}

Similarly, based on the results of the air quality monitoring stations in Metropolitan Lima, the values without dimension were obtained for each parameter of the 2 selected monitoring stations. These values are presented in Table VI.

TABLE VI. NON-DimENSIONAL MONITORING DATA IN METROPOLITAN LIMA

\begin{tabular}{|c|l|l|l|l|}
\hline \multirow{2}{*}{ Parameter } & \multicolumn{2}{|l|}{ 2018-2019 period } & 2020 period \\
\cline { 2 - 5 } & $\boldsymbol{V M T}$ & $\boldsymbol{C A R}$ & $\boldsymbol{V M T}$ & $\boldsymbol{C A R}$ \\
\hline$C_{1}$ & 0.808 & 0.611 & 0.598 & 0.329 \\
\hline$C_{2}$ & 0.487 & 0.428 & 0.353 & 0.235 \\
\hline$C_{3}$ & 0.113 & 0.073 & 0.116 & 0.061 \\
\hline$C_{4}$ & 0.082 & 0.117 & 0.066 & 0.105 \\
\hline
\end{tabular}

Step 5: Triangular Whitenization Functions

With Table $\mathrm{V}$, the triangular whitenization functions and the values for each parameter were determined as shown in Fig. 3.

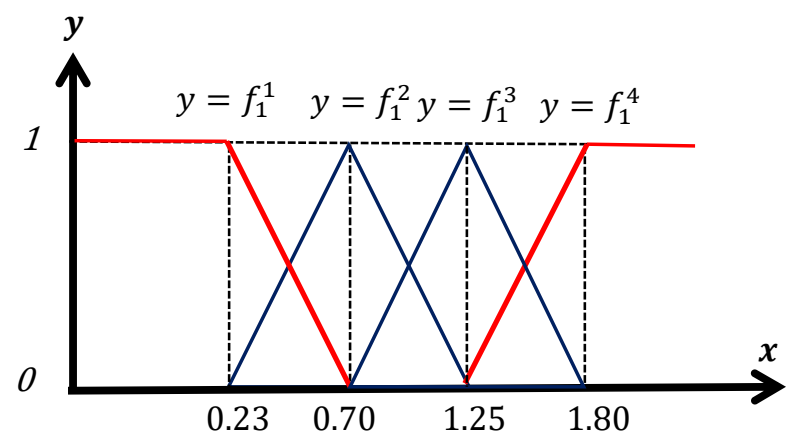

Fig. 3. CTWF for the Parameter of Particles with a Diameter of Less than 10 $\mu \mathrm{m}$ Parameter $\left(\mathrm{PM}_{10}\right)$.

Therefore, the expressions (14) - (17) were obtained.

$f_{1}^{1}(x)=\left\{\begin{array}{cc}1, & x \in[0,0.235] \\ \frac{0.707-x}{0.707-0.235} & x \in[0.235,0.707] \\ 0 & x \in[0.707, \infty]\end{array}\right.$

$f_{1}^{2}(x)=\left\{\begin{array}{cl}0, & x \notin[0.235,1.255] \\ \frac{x-0.235}{0.707-0.235} & x \in[0.235,0.707] \\ \frac{1.255-x}{1.255-0.707} & x \in[0.707,1.255]\end{array}\right.$

$f_{1}^{3}(x)=\left\{\begin{array}{cl}0, & x \notin[0.707,1.803] \\ \frac{x-0.707}{1.255-0.707} & x \in[0.707,1.255] \\ \frac{1.803-x}{1.803-1.255} & x \in[1.255,1.803]\end{array}\right.$

$f_{1}^{4}(x)=\left\{\begin{array}{cc}1, & x \in[1.803, \infty] \\ \frac{x-1.255}{1.803-1.255} & x \in[1.255,1.803] \\ 0 & x \in[0,1.255]\end{array}\right.$

Then, the values obtained for each period and location are displayed in Table VII and Table VIII.

TABLE VII. VALUES OF CTWF FOR VMT

\begin{tabular}{|c|c|l|l|l|}
\hline Period of 2018-2019 & $\boldsymbol{f}_{\boldsymbol{j}(\boldsymbol{x})}^{\mathbf{1}}$ & $\boldsymbol{f}_{\boldsymbol{j}(\boldsymbol{x})}^{\mathbf{2}}$ & \multicolumn{1}{|c|}{$\boldsymbol{f}_{\boldsymbol{j}(\boldsymbol{x})}^{\mathbf{3}}$} & $\boldsymbol{f}_{\boldsymbol{j}(\boldsymbol{x})}^{\mathbf{4}}$ \\
\hline$C_{1}$ & 0.000 & 0.816 & 0.183 & 0.000 \\
\hline$C_{2}$ & 0.000 & 0.833 & 0.167 & 0.000 \\
\hline$C_{3}$ & 1.000 & 0.000 & 0.000 & 0.000 \\
\hline$C_{4}$ & 1.000 & 0.000 & 0.000 & 0.000 \\
\hline Period of 2020 & $\boldsymbol{f}_{\boldsymbol{j}(\boldsymbol{x})}^{\mathbf{1}}$ & $\boldsymbol{f}_{\boldsymbol{j}(\boldsymbol{x})}^{\mathbf{2}}$ & $\boldsymbol{f}_{\boldsymbol{j}(\boldsymbol{x})}^{\mathbf{3}}$ & $\boldsymbol{f}_{\boldsymbol{j}(\boldsymbol{x})}^{\mathbf{4}}$ \\
\hline$C_{1}$ & 0.232 & 0.768 & 0.000 & 0.000 \\
\hline$C_{2}$ & 0.000 & 0.971 & 0.029 & 0.000 \\
\hline$C_{3}$ & 1.000 & 0.000 & 0.000 & 0.000 \\
\hline$C_{4}$ & 1.000 & 0.000 & 0.000 & 0.000 \\
\hline
\end{tabular}


TABLE VIII. VALUES OF CTWF FOR CAR

\begin{tabular}{|c|l|c|c|c|}
\hline Period of 2018-2019 & $\boldsymbol{f}_{\boldsymbol{j}(\boldsymbol{x})}^{\mathbf{1}}$ & $\boldsymbol{f}_{\boldsymbol{j}(\boldsymbol{x})}^{\mathbf{2}}$ & $\boldsymbol{f}_{\boldsymbol{j}(\boldsymbol{x})}^{\mathbf{3}}$ & $\boldsymbol{f}_{\boldsymbol{j}(\boldsymbol{x})}^{\mathbf{4}}$ \\
\hline$C_{1}$ & 0.203 & 0.797 & 0.000 & 0.000 \\
\hline$C_{2}$ & 0.000 & 0.894 & 0.106 & 0.000 \\
\hline$C_{3}$ & 1.000 & 0.000 & 0.000 & 0.000 \\
\hline$C_{4}$ & 1.000 & 0.000 & 0.000 & 0.000 \\
\hline Period of 2020 & $\boldsymbol{f}_{\boldsymbol{j}(\boldsymbol{x})}^{\mathbf{1}}$ & $\boldsymbol{f}_{\boldsymbol{j}(\boldsymbol{x})}^{2}$ & $\boldsymbol{f}_{\boldsymbol{j}(\boldsymbol{x})}^{\mathbf{3}}$ & $\boldsymbol{f}_{\boldsymbol{j}(\boldsymbol{x})}^{\mathbf{4}}$ \\
\hline$C_{1}$ & 0.800 & 0.200 & 0.000 & 0.000 \\
\hline$C_{2}$ & 0.417 & 0.583 & 0.000 & 0.000 \\
\hline$C_{3}$ & 1.000 & 0.000 & 0.000 & 0.000 \\
\hline$C_{4}$ & 1.000 & 0.000 & 0.000 & 0.000 \\
\hline
\end{tabular}

Step 6: Definition of the Clustering Weight

The clustering weight $\left(\eta_{i}\right)$ of each parameter was determined using Shannon entropy. For this, the following procedure:

1) The values of the parameters of the Air Quality index were normalized. These values are presented in Table IX.

TABLE IX. NORMALIZED VALUES OF EACH PARAMETER

\begin{tabular}{|c|l|l|l|l|}
\hline Parameter & $\begin{array}{l}\text { Good } \\
\left(\boldsymbol{\lambda}_{\mathbf{1}}\right)\end{array}$ & $\begin{array}{l}\text { Moderate } \\
\left(\boldsymbol{\lambda}_{\mathbf{2}}\right)\end{array}$ & $\begin{array}{l}\text { Poor } \\
\left(\boldsymbol{\lambda}_{\mathbf{3}}\right)\end{array}$ & $\begin{array}{l}\text { Threshold } \\
\text { of care }\left(\boldsymbol{\lambda}_{\mathbf{4}}\right)\end{array}$ \\
\hline$C_{1}$ & 0.059 & 0.177 & 0.314 & 0.451 \\
\hline$C_{2}$ & 0.027 & 0.081 & 0.324 & 0.568 \\
\hline$C_{3}$ & 0.063 & 0.188 & 0.313 & 0.437 \\
\hline$C_{4}$ & 0.063 & 0.188 & 0.313 & 0.437 \\
\hline
\end{tabular}

2) The entropy $H_{j}$ of each criterion $C_{j}$ was calculated through (9). The results are presented in Table $\mathrm{X}$.

TABLE X. VALUES FOR EACH PARAMETER

\begin{tabular}{|l|l|l|l|l|}
\hline Entropy & $\mathbf{C}_{\mathbf{1}}$ & $\mathbf{C}_{\mathbf{2}}$ & $\mathbf{C}_{\mathbf{3}}$ & $\mathbf{C}_{\mathbf{4}}$ \\
\hline $\mathrm{H}_{\mathrm{j}}$ & 0.863 & 0.713 & 0.875 & 0.875 \\
\hline Degree of divergence & $\mathbf{C}_{\mathbf{1}}$ & $\mathbf{C}_{\mathbf{2}}$ & $\mathbf{C}_{\mathbf{3}}$ & $\mathbf{C}_{\mathbf{4}}$ \\
\hline div $_{\mathrm{j}}$ & 0.137 & 0.287 & 0.125 & 0.125 \\
\hline Clustering Weight & $\mathbf{C}_{\mathbf{1}}$ & $\mathbf{C}_{\mathbf{2}}$ & $\mathbf{C}_{\mathbf{3}}$ & $\mathbf{C}_{4}$ \\
\hline $\mathrm{W}_{\mathrm{j}}=\mathrm{n}_{\mathrm{j}}$ & 0.204 & 0.426 & 0.186 & 0.185 \\
\hline
\end{tabular}

Step 7: Definition of the Clustering Coefficients

The values of the clustering coefficients $\left(\sigma_{i}^{k}\right)$ were calculated using (12). Then, the results for each period and location are displayed in Table XI and Table XII.

TABLE XI. VALUES OF CLUSTERING COEFFICIENTS FOR VMT

\begin{tabular}{|c|c|c|c|c|}
\hline Period of 2018-2019 & $\boldsymbol{f}_{\boldsymbol{j}(\boldsymbol{x})}^{\mathbf{1}}$ & $\boldsymbol{f}_{\boldsymbol{j}(\boldsymbol{x})}^{\mathbf{2}}$ & $\boldsymbol{f}_{\boldsymbol{j}(\boldsymbol{x})}^{\mathbf{3}}$ & $\boldsymbol{f}_{\boldsymbol{j}(\boldsymbol{x})}^{\mathbf{4}}$ \\
\hline$\sigma_{j}^{k}$ & 0.371 & 0.521 & 0.108 & 0.000 \\
\hline Period of 2020 & $\boldsymbol{f}_{\boldsymbol{j}(\boldsymbol{x})}^{\mathbf{1}}$ & $\boldsymbol{f}_{\boldsymbol{j}(\boldsymbol{x})}^{2}$ & $\boldsymbol{f}_{\boldsymbol{j}(\boldsymbol{x})}^{\mathbf{3}}$ & $\boldsymbol{f}_{\boldsymbol{j}(\boldsymbol{x})}^{\mathbf{4}}$ \\
\hline$\sigma_{j}^{k}$ & 0.418 & 0.569 & 0.012 & 0.000 \\
\hline
\end{tabular}

TABLE XII. VALUES OF CLUSTERING COEFFICIENTS FOR CAR

\begin{tabular}{|c|c|c|c|c|}
\hline Period of 2018-2019 & $\boldsymbol{f}_{j(x)}^{\mathbf{1}}$ & $\boldsymbol{f}_{j(x)}^{2}$ & $\boldsymbol{f}_{j(x)}^{3}$ & $\boldsymbol{f}_{j(x)}^{4}$ \\
\hline$\sigma_{j}^{k}$ & 0.412 & 0.543 & 0.045 & 0.000 \\
\hline Period of 2020 & $\boldsymbol{f}_{j(x)}^{\mathbf{1}}$ & $\boldsymbol{f}_{j(x)}^{2}$ & $\boldsymbol{f}_{j(x)}^{3}$ & $\boldsymbol{f}_{j(x)}^{\mathbf{4}}$ \\
\hline$\sigma_{j}^{k}$ & 0.711 & 0.289 & 0.000 & 0.000 \\
\hline
\end{tabular}

\section{Step 8: Definition of Maximum Clustering Coefficient}

Finally, the condition was applied: if $\max \left\{\sigma_{i}^{k}\right\}=\sigma_{i}^{k^{*}}$ it is decided that the object $\mathrm{i}$ belongs to the Grey class $\mathrm{k}^{*}$; for each monitoring station. Therefore, the maximum value obtained is presented in Table XIII.

TABLE XIII. VALUES OF MÁX $\sigma_{i}^{k^{*}}$ AND AQI

\begin{tabular}{|l|l|l|l|l|}
\hline \multirow{3}{*}{ Station } & \multicolumn{2}{|l|}{$\mathbf{2 0 1 8 - 2 0 1 9}$ period } & $\mathbf{2 0 2 0}$ period \\
\cline { 2 - 5 } & Max $\sigma_{j}^{k}$ & $\begin{array}{l}\text { Air Quality } \\
\text { Index }\end{array}$ & Max $\sigma_{j}^{k}$ & $\begin{array}{l}\text { Air Quality } \\
\text { Index }\end{array}$ \\
\hline VMT & 0.521 & Moderate & 0.569 & Moderate \\
\hline CAR & 0.543 & Moderate & 0.711 & Good \\
\hline
\end{tabular}

\section{B. Discussion about Results on the Case Study}

On March 15, a state of emergency was decreed, making Peru the first country in South America to take strict measures to prevent an increase in positive cases of COVID 19. These measures include mandatory social isolation (through a national blockade) and a complete blockade of the border, starting on March 16. On March 18, a curfew was enacted to support mandatory social distancing measures because people did not adhere to lockdown restrictions, and the use of private vehicles was banned as of March 19. Despite all the health measures implemented, the number of confirmed cases in Peru exceeded 100,000 on May 20 [2]. The impact of the measures implemented during the state of emergency was to stop production activities, as reflected by electricity consumption [2].

The decrease in electricity demand reflects the freezing of production activities and possible sources of emissions of atmospheric pollutants. By June 30, 2020, air pollution in the two stations, in terms of PM10, PM2.5 and NO2 and CO2, had decreased (Table XIII), it is observed that there was an improvement in air quality in the station of CAR, being the index of good air quality, while in the VMT station it remains moderate. Likewise, compared to the historical period (the previous two years 2018-2019), it is show that the air quality index in the VMT and CAR stations is moderate [11].

Based on these results from the stations air quality it can be inferred that the northern part as well as the southern part of the territory of Metropolitan Lima has air quality problems, and with measures proposed by the state of emergency it has improved. This due to the fact that, as we can see in Fig. 4, the variation of the concentration of the four parameters during the years 2016 - 2020 for the period of March - June in CAR station, taking into account that the data from the years 2018 were used to perform the calculations of the study - 2019 (period without quarantine) and 2020 (period in quarantine), and show that during the years analyzed a reduction in concentration is observed for the four parameters. On the other hand, in the graph for the PM 2.5 parameter, no information is recorded for the year 2017, so only a trend line was drawn.

Followed, a summarize of the graphic representation is shown in Fig. 5 for a better understanding of the data obtained from the parameters studied in Carabayllo (CAR).

On the other hand, the variation of the concentration of the four parameters is shown in Fig. 6, during the years 2016 - 
2020 for the months of March - June in VMT station, taking into account that the data from the years 2018 were used to perform the calculations of the study - 2019 (period without quarantine) and 2020 (period in quarantine). The values show that during the years analyzed a reduction in concentration is observed for the parameters of PM10, PM2.5 and CO, while NO2 shows an increase of around $2 \%$, this can be explained because an average of the years 2018 - 2019, which present a considerable variation of the parameter.

Followed, a summarize of the graphic representation is shown in Fig. 7 for a better understanding of the data obtained from the parameters studied in Villa Maria del Triunfo (VMT).

The dispersion of pollutants in the atmosphere is subject to the meteorological and geographical conditions of the specific place for the city of Lima, the factors that influence the most is the atmospheric layer of thermal inversion and the action of the winds, the latter during March. In 2020, it presented a predominant direction from south to north of Lima with average daily velocity values of 2 to $4 \mathrm{~m} / \mathrm{s}$ at a height of $10 \mathrm{~m}$ from the Surface [12], as shown in Fig. 8.

On the other hand, with respect to the atmospheric layer of thermal inversion, a lower height was evidenced in March 2020 in the southern area of Lima compared to the other areas. It is clear that in the VMT station the height is on average 300 $\mathrm{m}$ different from the Carabayllo station with a height above $400 \mathrm{~m}$.
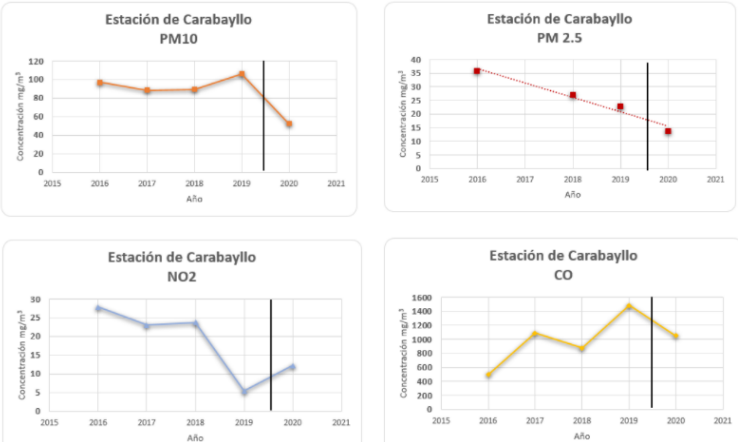

Fig. 4. Graphic Representation for the Four Parameters at Carabayllo (CAR).

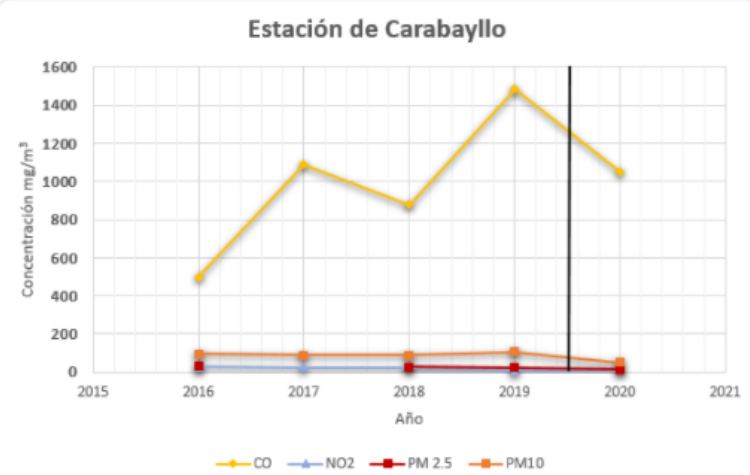

Fig. 5. Graphic Representation Summarize for the Four Parameters at Carabayllo (CAR).
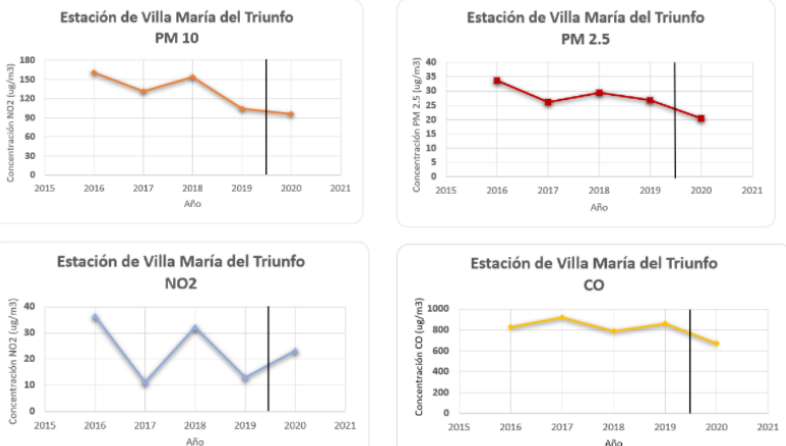

Fig. 6. Graphic Representation for the Four Parameters at Villa Maria del Triunfo (VMT).

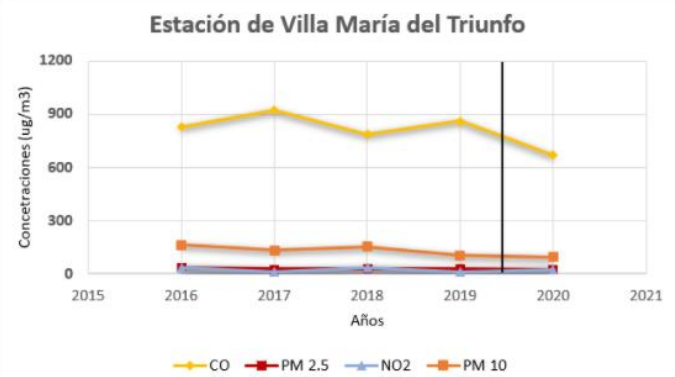

Fig. 7. Graphic Representation Summarize for the Four Parameters at Villa Maria del Triunfo (VMT).

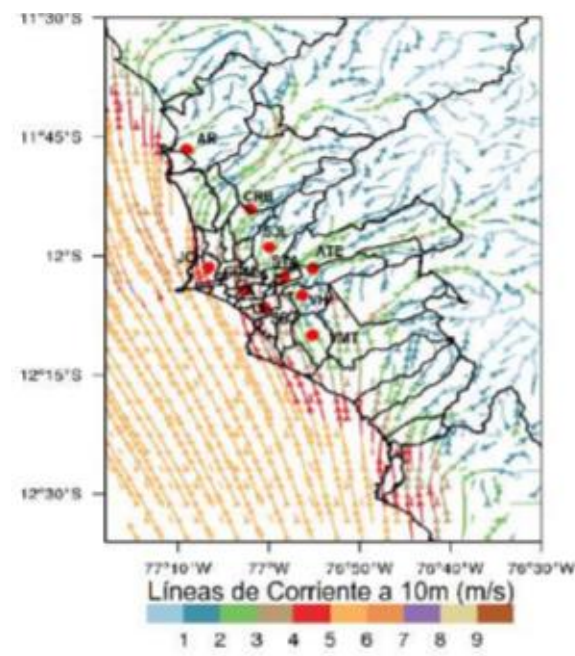

Fig. 8. Power Lines at 10m High during March 2020 in Lima.

Therefore, North Lima evidenced better dispersion conditions than South Lima during March 2020, based on the greater space available for the dispersion of pollutants (greater height of the planetary boundary layer) with respect to wind conditions; the conditions were similar in both areas, as shown in Fig. 9.

In this sense, the CAR station registered a more substantial improvement in air quality during the quarantine period compared to the VMT station because it is located in the north and south of Lima, respectively [13]. 


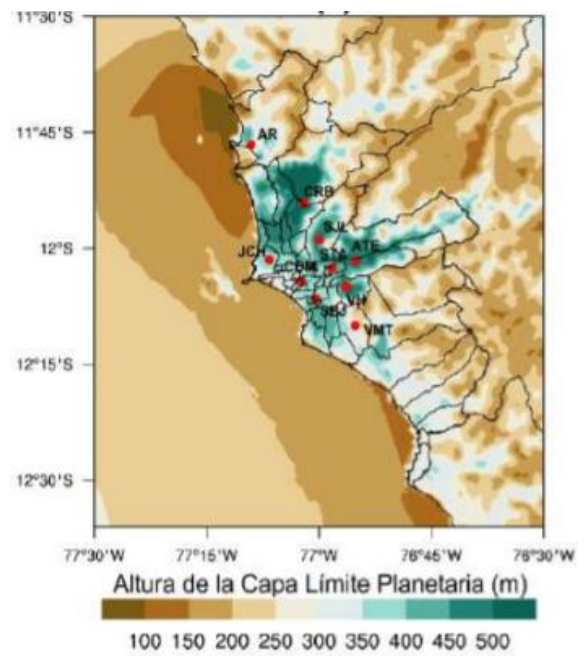

Fig. 9. Average Height of the Planetary Boundary Layer in Lima during March 2020.

\section{Discussion about the Methodology}

Unlike the studies carried out in China and Brazil of air quality during the COVID-19 pandemic, the present work carried out a comprehensive methodology using the Grey Clustering method and the Shannon entropy for the same study.

The Grey Clustering method is the most appropriate in matters of high uncertainty [14], such as the evaluation of air quality, where each parameter varies according to environmental conditions.

On the other hand, the Shannon entropy method is very suitable for evaluating air quality after determining the grouping weights $\left(\eta_{j}\right)$ for each parameter objectively, without the need to consult an expert and that reduces evaluation costs. Furthermore, this method has multiple applications such as in studies of social conflicts or social impact evaluations [15], due to its great capacity to process information and reduce subjectivity in evaluations.

\section{CONCLUSION}

The air quality in Metropolitan Lima during the national closure in the framework of the state of emergency due to COVID-19 presented significant improvements compared to its similar in 2018-2019; specifically the north of Lima was also favored by the meteorological conditions. This allowed its classification as good quality, unlike the southern zone, which although it showed an improvement, the classification remains of moderate quality.

The Grey Clustering methodology made it possible to evaluate air quality in a comprehensive way based on the most relevant atmospheric pollutants in the study area, unlike conventional methodologies that evaluate individually with respect to each parameter, and also considers the uncertainty within the This analysis is therefore also applicable to problems with insufficient data, on the other hand, in reference to Shannon's entropy, it was possible to determine the weights of the parameters in an objective manner, free of subjective assessments.

The work generates information of vital importance for future research on air quality using the Grey Clustering methodology as well as its integration into environmental regulatory bodies.

\section{REFERENCES}

[1] A. O. Strontsitska, O. Pavliuk, R. Dunaev, and R. Derkachuk, "Forecast of the number of new patients and those who died from COVID-19 in Bahrain," 2020 Int. Conf. Decis. Aid Sci. Appl. DASA 2020, pp. 422 426, Nov. 2020, doi: 10.1109/DASA51403.2020.9317122.

[2] J. A. Lossio-Ventura, H. Alatrista-Salas, K. Barrena, E. Linos, M. Nunez-Del-Prado, and A. Talavera, "DYVIC: DYnamic VIrus Control in Peru," Proc. - 2020 IEEE Int. Conf. Bioinforma. Biomed. BIBM 2020, pp. 2264-2267, Dec. 2020, doi: 10.1109/BIBM49941.2020.9313419.

[3] J. C et al., "Air quality characteristics in Wuhan (China) during the 2020 COVID-19 pandemic," Environ. Res., vol. 195, Apr. 2021, doi: 10.1016/J.ENVRES.2021.110879.

[4] L. Y. K. Nakada and R. C. Urban, "COVID-19 pandemic: Impacts on the air quality during the partial lockdown in São Paulo state, Brazil," Sci. Total Environ., vol. 730, p. 139087, Aug. 2020, doi: 10.1016/J.SCITOTENV.2020.139087.

[5] S. Tabik et al., "COVIDGR Dataset and COVID-SDNet Methodology for Predicting COVID-19 Based on Chest X-Ray Images," IEEE J. Biomed. Heal. Informatics, vol. 24, no. 12, pp. 3595-3605, Dec. 2020, doi: 10.1109/JBHI.2020.3037127.

[6] R. M. Arias Veĺasquez, Y. L. Romero Ramos, and J. Noel, "Citizen science approach for spatiotemporal modelling of air pollution quality and traffic in Lima, Peru," SHIRCON 2019 - 2019 IEEE Sci. Humanit. Int. Res. Conf., Nov. 2019, doi: 10.1109/SHIRCON48091.2019.9024879.

[7] A. Delgado, "Citizen criminality assessment in lima city using the grey clustering method," 2017, doi: 10.1109/INTERCON.2017.8079662.

[8] Y. Ji, G. H. Huang, and W. Sun, "Risk assessment of hydropower stations through an integrated fuzzy entropy-weight multiple criteria decision making method: A case study of the Xiangxi River," Expert Syst. Appl., vol. 42, pp. 5380-5389, 2015.

[9] A. Delgado and I. Romero, "Environmental conflict analysis on a hydrocarbon exploration project using the Shannon entropy," in Proceedings of the 2017 Electronic Congress, E-CON UNI 2017, Jun. 2017, vol. 2018-January, pp. 1-4, doi: 10.1109/ECON.2017.8247309.

[10] L. Sifeng and L. Yi, Grey Systems, Theory and Applications. Chennai; India: Springer, 2010.

[11] A. Delgado, E. L. Huamaní, H. Obispo-Mego, and D. Justo-López, "Analysis of web platforms of learning management systems for distance education in the face of social isolation," Int. J. Adv. Trends Comput. Sci. Eng., vol. 9, no. 5, 2020, doi: 10.30534/ijatcse $12020 / 154952020$

[12] A. Delgado and I. Romero, "Applying the Grey Systems Theory to Assess Social Impact from an Energy Project," in 2018 IEEE XXV International Conference on Electronics, Electrical Engineering and Computing (INTERCON), Aug. 2018, pp. 1-4, doi: 10.1109/INTERCON.2018.8526372.

[13] Q. Wang, Y. Guo, T. Ji, X. Wang, B. Hu, and P. Li, "Towards Combatting COVID-19: A Risk Assessment System," IEEE Internet Things J., pp. 1-1, 2021, doi: 10.1109/JIOT.2021.3070042.

[14] S. Liu, C. Lin, and Y. Yang, "Several problems need to be studied in grey system theory," in 2017 IEEE International Conference on Grey Systems and Intelligent Services, GSIS 2017, Oct. 2017, pp. 1-4, doi: 10.1109/GSIS.2017.8077658.

[15] M. G. B. Borja, A. Delgado, S. Lescano, and J. E. Luyo, "New Approach to Develop Knowledge-Based System for Environmental Conflicts Analysis Using Fuzzy Logic and Grey Systems," Dec. 2018, doi: 10.1109/ANDESCON.2018.8564666. 